\title{
SISTEM PAKAR DIAGNOSA PENYAKIT PARU-PARU MENGGUNAKAN METODE FORWARD CHAINING BERBASIS ANDROID
}

\section{MOCH FIKRI SYAIFULLOH}

Teknik Informatika, Fakultas Teknik

Universitas Maarif Hasyim Latif, Sidoarjo, Indonesia

e-mail : mochfikri240@gmail.com

\begin{abstract}
ABSTRAK
Dalam perkembangan teknologi seseorang akan memanfaatkan kecanggihan dan kemudahan tersebut untuk memudahkan setiap pekerjaan dan juga hal-hal lainya. Beberapa contoh perkembangan teknologi yaitu membuat aplikasi sistem pakar dengan metode forward chaining. Penyakit paru-paru merupakan penyakit yang tingkat kematiaannya cukup luas dan dapat menyerang siapa saja tanpa memandang usia dan suku bangsa. Dalam kehidupan sehari-hari kita banyak menjumpai penyakitnya antara lain Asma, TBC, Pheneumotoraks, pneumonia dan legionnaries. Bantuan teknologi yang ada akan memudahkan dan memberikan fungsi yang sangat berharga. Diagnosa atau gejala-gejala yang sudah kita dapatkan melalui wawancara langsung kepada seorang dokter spesialis diimplementasikan dalam bentuk aplikasi yang mana disini penulis menggunakan berbasis android sehingga masyarakat mampu mendapatkan informasi dengan efektif dan cepat serta aman digunakan juga.
\end{abstract}

Kata kunci : sistem pakar, forward chaining, penyakit paru-paru

\section{PENDAHULUAN}

Penyakit paru-paru merupakan penyakit yang tingkat kematiaannya cukup luas. Dalam kehidupan sehari-hari kita banyak menjumpai penyakitnyaantara lain Asma, TBC, Pheneumotoraks, pneumonia dan legionnaries. Tetapi hal itu tidak boleh dianggap remeh, Karena fungsi dari paru-paru sebagai alat pernafasan manusia sangat penting.

Ikha Martha Amalia [1], dalam penelitiannya menjelaskan tentang bagaimana menghasilkan sebuah program yang menerapkan metode Certainy factor. Perbedaan dengan penelitian sekarang ini adalah program yang dihasilkan tidak hanya menggunakan web tetapi dengan berbasis android sehingga bisa memudahkan masyarakat.

Ibnu Titto Dessetiadi [2], dalam penelitiannya menggunakan metode bayes, pengelompokan penyakit paru-paru yang digunakan berbasis web. Klasifikasi pada metode bayes membantu mendiagnosa penyakit paru-paru dengan mempresentasikan suatu himpunan variabel tapi keakuratannya kurang.

Berdasarkan uraian tersebut, penulis ingin mencoba memberikan solusi kepada masyarakat agar dapat lebih mengetahui gejala penyakit paruparu.

\section{METODOLOGI PENELITIAN}

\section{Kerangka Berpikir}

Kerangka berpikir merupakan suatu gambaran secara jelas akan pembahasan yang akan dipecahkan hingga mendapatkan suatu solusi yang baik. Dimana setiap alur dan tahapannya dibuat untuk membantu penulis memusatkan pada permasalahan yang diteliti untuk memahami hubungan antara variabel tertentu yang telah dipilih dan mempermudah penulis memahami dari penelitian yang dilakukan. Adapun kerangka berpikir dalam penulisan ini ditunjukkan pada gambar 1.

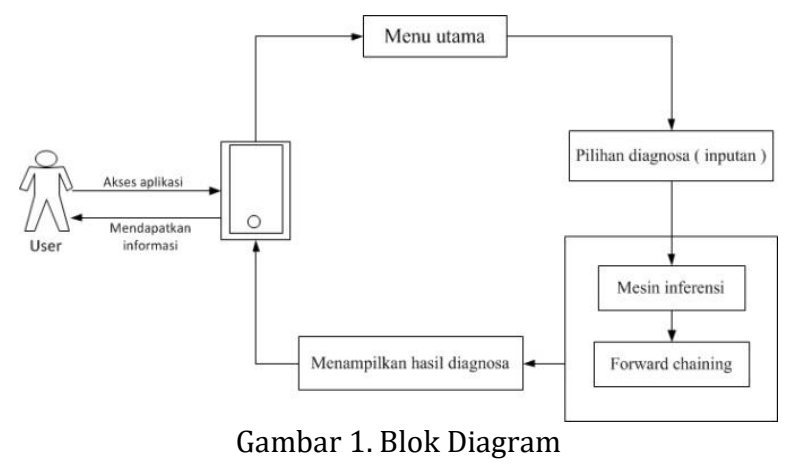

Flowchart

Gambar 2 menjelaskan proses penelusuran dengan metode forward chaining yangdimulai dari memasukkandata gejala yang dialami pasien. Jika ditemukan sebuah premise sesuai gejala yang telah dimasukkan, maka dapat ditarik kesimpulan dari premise tersebut disimpan kedalam hasil diagnosa penyakit paru-paru dan menjadi kesimpulan. Begitu seterusnya hingga rules ditelusuri hingga mendekati penyakit, setelah rules diperiksa maka 
akan diperoleh hasil berupa jenis penyakit paruparu.

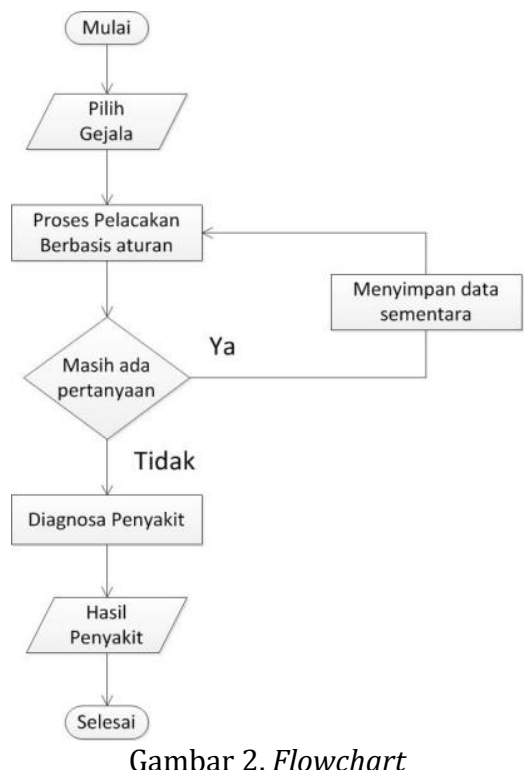

\section{Kecerdasan Buatan}

Artifical Intelligence (AI) adalah disipilin ilmu yang mempelajari tentang bagaimana caranya agar membuat mesin dapat berjalan sendiri sesuai dengan perintah yang diinputkan.

\section{Sistem Pakar}

Merupakan sistem yang berbasis komputer menggunakan pengetahuan, fakta sertateknik penalaran dalam memecahkan masalah. Dalam sumber yang lain, sistem pakar atau Expert System yaitu suatu program yang dirancang untuk memodelkan kemampuan penyelesaian masalah dengan metode tertentu oleh seorang pakar.

\section{Forward Chaining}

Metode forward chaining dimulai dari sejumlah fakta lama, untuk mendapatkan suatu fakta barudengan memakai rule yang ada, kemudian dilanjutkan sampai mendapatkan fakta yang sesuai. Metode ini digunakan juga untuk menyelesaikan masalah berdasarkan kondisi yang ada, dimana pada metode ini dimulai dari pencarian premis atau data menuju konklusi.Sebagai contoh, asumsikan listing berikut ini valid, masing-masing variable dari setiap rule menginginkan nilai benar (true) dan tujuannya adalah variabel $\mathrm{G}$ :

R1 : JIKA A DAN C MAKA E;

R2 : JIKA D DAN C MAKA $\mathrm{H}$;

R3 : JIKA B DAN E MAKA F;

R4 : JIKA B MAKA C;

R5 : JIKA F MAKA G;

\section{Penyakit Paru-Paru}

Paru-paru merupakan salah satu organ pernafasan yang sangat penting, tetapi rentan terhadap berbagai penyakit. Oleh karena itu dalam Sistem Ekskresi, paru-paru berfungsi untuk melalukan proses pertukaran antara gas oksigen dan karbondioksida agar pernafasan berjalan lancar.

Berdasarkan pemahaman di atas, berikut jenis penyakit paru-paru yang banyak dialami oleh masyarakat yaitu TBC, Pneumotoraks, Pheunomia, Legionnaries dan Sesak Nafas (asma).

\section{Activity Diagram}

Activity diagram pengguna ini menggambarkan proses interaksi antara user dengan sistem. Dimana diagram dibuat untuk menjelaskan aktifitas komputer maupun gambaran alur kontrol secara garis besar. Bentuk visual dari alur kerja yang berisi aktifitas serta tindakan, yang berisi pilihan, pengulangan dan concurrency. Berikut pada gambar 3 adalah gambar Activity diagram.

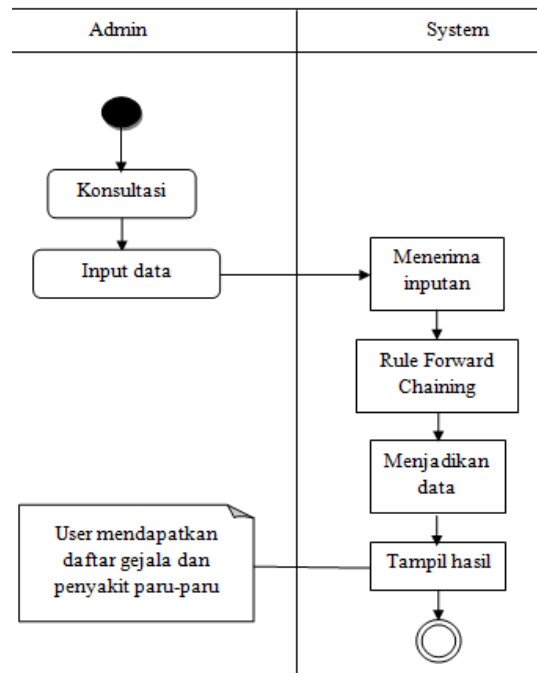

Gambar 3. Activity Diagram

\section{Use case}

Diagram use case digunakan untuk memodelkan fungsional sistem yang digunakan oleh pengguna sistem. Berikut ini adalah diagram use case untuk aplikasi sistem pakar diagnosa penyakit paru-paru dengan metode forward chaining.

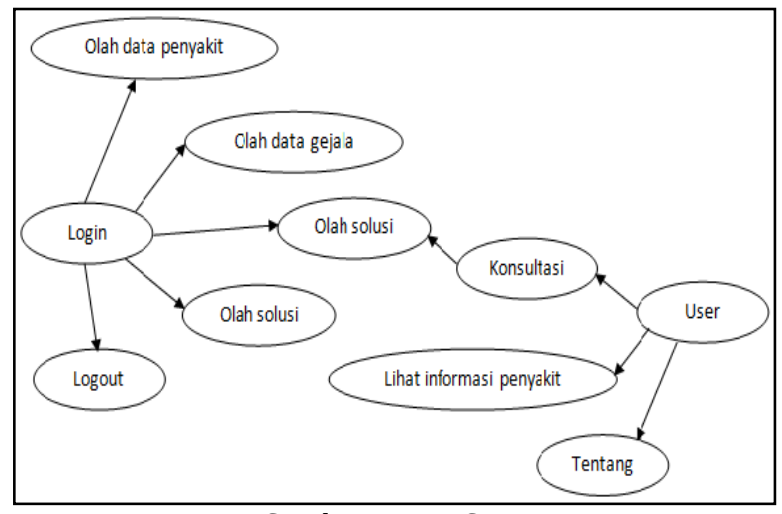

Gambar 4. Use Case 


\section{Entity Relationship Diagram}

Berikut pada gambar 5 adalah ERD yang digunakan untuk menghasilkan rancangan database yang baik.

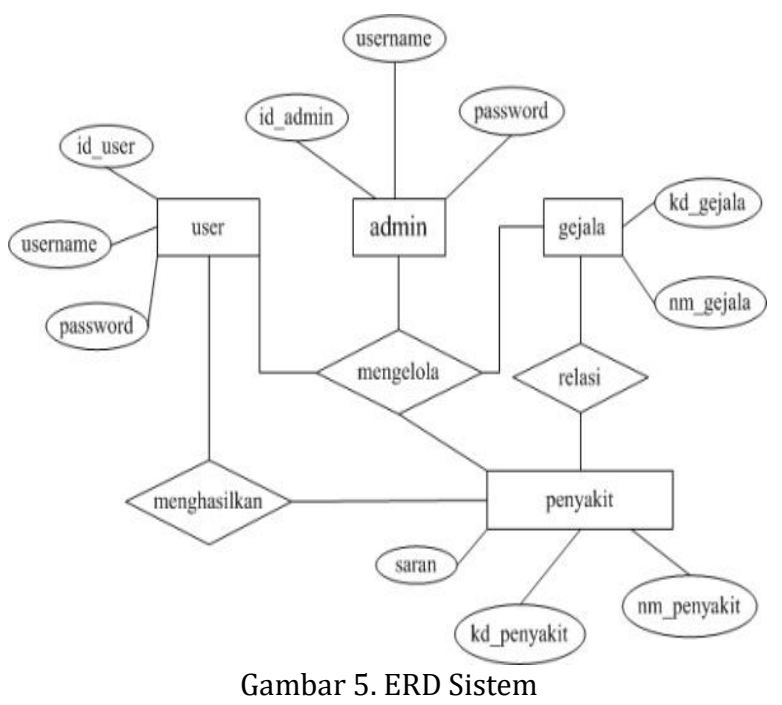

\section{IMPLEMENTASI DAN PEMBAHASAN}

\section{User Interface}

User Interface bukan hanya untuk memudahkan interaksi antarmanusia dengan perangkat (mesin) tetapi juga untuk mempercantik tampilan perangkat. Antarmuka pengguna untuk aplikasi Android juga dibuat menggunakan hierarki layout (objekViewGroup) dan widget (obyek View). Layout adalah container yang mengontrol bagimana tampilan diposisikan pada layar Widget komponen UI seperti tombol dan kotak teks.

\section{Tampilan Awal}

Sebelum masuk ke tampilan utama diharuskan untuk login terlebih dahulu agar bisa masuk. Form login digunakan untuk masuk halaman utama dengan sebelumnya mendaftar terlebih dahulu. Login menggunakan username dan password. Dapat dilihat pada Gambar 6.
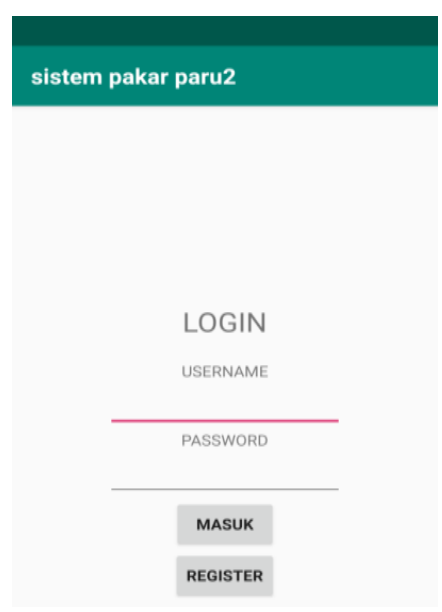

Gambar 6. Form Login
Tampilan awal aplikasi adalah halaman awal diagnose pada android sebelum melakukan diagnose atau konsultasi. Disini User dapat memilih menu-menu yang terdapat dalam aplikasi ini. Berikut ini adalah tampilan yang menjelaskan bagaimana sistem bekerja di setiap menumenunya. Ada beberapa menu yang pertama adalah menu awal atau halaman utama diagnose penyakit paru-paru yang berisi empat menu. Halaman awal diagnose penyakit paru-paru terdapat menu Diagnosa, Tentang, Info, dan Keluar. Dapat dilihat pada Gambar 7.

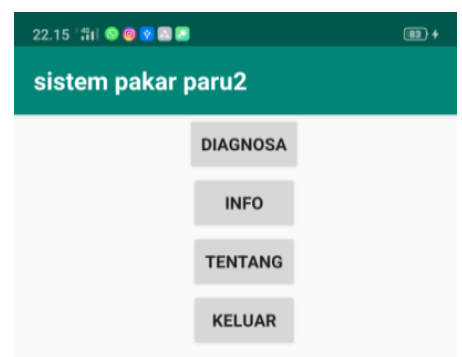

Gambar 7. Halaman Utama

\section{Diagnosa}

Halaman menu Diagnosa, user dapat langsung memilih gejala yang dialami dan bisa langsung melakukan diagnosa. Dapat dilihat pada gambar 8.

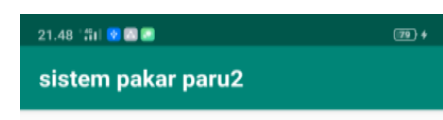

$$
\text { apakah anda mengalami batuk }
$$
berdahak?

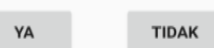

Gambar 8. Menu Diagnosa

Info

Halaman menu Info berisi tentang cara mengindari atau mencegah penyakit paru-paru dari pola makan dan kebiasaan sehari-hari. Menu Info dapat dilihat pada Gambar 9.

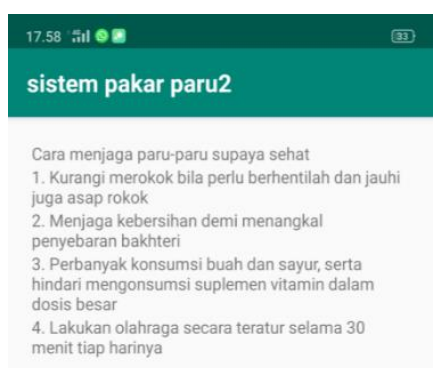

Gambar 9. Menu Info 


\section{Tabel Diagnosa Penyakit Paru-Paru}

Pada tabel 1 berisi data diagnose penyakit paru-paru yang digunakan sebagai data input dan output pada aplikasi sistem pakar diagnose penyakit paru-paru. Untuk jenis gejala memiliki kode (G) sedangkan untuk penyakit memiliki kode (P). Untuk gejala ada 20 gejala terbagi dengan 5 penyakit dapat dilihat pada tabel 1.

Tabel 1. Data Diagnosa Penyakit Paru-Paru

\begin{tabular}{l|l|l}
\hline $\begin{array}{l}\text { Kode } \\
\text { gejala }\end{array}$ & \multicolumn{1}{|c|}{ Nama Gejala } & Kode Penyakit \\
\hline G01 & Batuk berdahak & P01,P02,P03 \\
\hline G02 & Sesak nafas & P01,P02,P03 \\
\hline G03 & Badan teras lemas & P01,P02 \\
\hline G04 & Penurunan nafsu makan & P01 \\
\hline G05 & Perasaan tidak enak & P01 \\
\hline G06 & Demam pada siang dan sore hari & P01 \\
\hline G07 & Penurunan berat badan & P01 \\
\hline G08 & Sering menderita infeksi pernafasan & P02 \\
\hline G09 & Pembengkakan pada kaki & P02 \\
\hline G10 & Pipi tampak memerah & P02 \\
\hline G11 & Sakit kepala & P02 \\
\hline G12 & Telapak tangan memerah & P02 \\
\hline G13 & Produksi lendir berlebihan & P05 \\
\hline G14 & Serangan terjado 3-4 kali setahun & P05 \\
\hline G15 & Gejala timbul malam hari & P05 \\
\hline G16 & Sakit pada dada & P03 \\
\hline G17 & Wajah memerah & P02 \\
\hline G18 & Gangguan penglihatan & P02 \\
\hline G19 & Selaput lendir yang berwarna kemerahan & P02 \\
\hline G20 & Batuk mengeluarkan darah & P01 \\
\hline P01 $=$ TBC & \\
P02 $=$ Pheunomotoraks & \\
P03 $=$ Pheunomia & \\
P04 $=$ Legionnaris & \\
P05 $=$ Asma &
\end{tabular}

\section{Uji Coba Aplikasi}

Uji coba aplikasi hasil diagnose penyakit paru-paru, maka dilakukan pengujian proses diagnosa. Dimana pada proses ini pengguna memilih gejala yang dialami, setelah itu sistem akan memproses inputan tersebut dan menampilkan hasil diagnosanya disertai dengan persentasi besarnya kepercayaan terhadap asumsi penyakit tersebut. Setelah proses pengujian berhasil dilakukan, hasil perhitungan dari sistem kemungkinan penyakitnya adalah pheunomotoraks. Maka hasil ditampilkan adalah pheunomotoraks. Dapat dilihat pada Gambar 9.

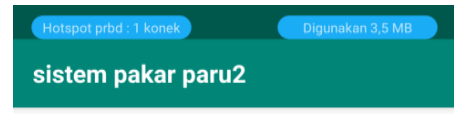

\section{HASIL DIAGNOSA}

dari gejala yang dialami, kemungkinan anda menderita penyakit.

PHEUNOMOTORAKS

Gambar 9. Menu Hasil Uji Coba

\section{Pengujian Akurasi}

Pengujian akurasi dilakukan untuk mengetahui performa keakurasian dari sistem pakar untuk memberikan hasil diagnosa kesimpulan jenis gejala yang diderita oleh pasien. Data yang diuji berjumlah 20 sampel data penyakit paru-paru yang didapat dari pakar sebagai dasar perbandingan pada pengujian. Pengujian yang dilakukan yaitu hasil yang diperoleh dari perhitungan sistem akan dibandingkan dengan hasil analisa pakar.

\begin{tabular}{c|c|l|l|c}
\multicolumn{6}{c}{ Tabel 2. Akurasi Tabel Diagnosa } \\
\hline No & Pasien & \multicolumn{1}{|c}{ Diagnosa Pasien } & \multicolumn{1}{|c}{$\begin{array}{c}\text { Diagnosa } \\
\text { Pakar }\end{array}$} & Akurasi \\
\hline 1 & A & TBC & TBC & 1 \\
\hline 2 & B & TBC & TBC & 1 \\
\hline 3 & C & $\begin{array}{l}\text { Kemungkinan terkena } \\
\text { Asma 45\% }\end{array}$ & Asma & 0 \\
\hline 4 & D & Asma & Asma & 1 \\
\hline 5 & E & Asma & Asma & 1 \\
\hline 6 & F & Pheumonia & Pheunomia & 1 \\
\hline 7 & G & Pheumonia & Pheunomia & 1 \\
\hline 8 & H & Pheumonia & Pheunomia & 1 \\
\hline 9 & I & $\begin{array}{l}\text { Kemungkinan terkena } \\
\text { Pheumonia 29 \% }\end{array}$ & Pheunomia & 0 \\
\hline 10 & J & Pheumonia & Pheunomia & 1 \\
\hline 11 & K & Legionnaries & Legionnaries & 1 \\
\hline 12 & L & Legionnaries & Legionnaries & 1 \\
\hline 13 & M & Legionnaries & Legionnaries & 1 \\
\hline 14 & N & Asma & Asma & 1 \\
\hline 15 & O & Asma & Asma & 1 \\
\hline 16 & P & Pneumotoraks & Pneumotoraks & 1 \\
\hline 17 & Q & $\begin{array}{l}\text { Kemungkinan terkena } \\
\text { TBC 33,3\% }\end{array}$ & TBC & 0 \\
\hline 18 & R & TBC & TBC & 1 \\
\hline 19 & S & Pneumotoraks & Pneumotoraks & 1 \\
\hline 20 & T & Pneumotoraks & Pneumotoraks & 1 \\
\hline & & &
\end{tabular}

\section{PENUTUP}

Aplikasi sistem penyakit paru-paru dapat membantu pasien dalam mengantisipasi dan menangani munculnya penyakit paru-paru. Aplikasi sistem pakar dapat dipakai sebagai media penerapan seorang ahli dalam menganalisa atau mendeteksi suatu penyakit dan dapat dijadikan sebagai alat bantu untuk pembelajaran. Sistem pakar ini dirancang untuk memberi solusi tentang penyakit paru-paru sekaligus memberikan penjelasan tentang penyakit paru-paru yang sering dialami.

Berdasarkan hasil uji lapangan mengunakan aplikasi sistem pakar, didapatkan hasil persentase sebesar $85 \%$ yang menunjukkan bahwa aplikasi cukup efektif.

Diharapkan kepada peneliti selanjutnya untuk dapat melakukan pengembangan terhadap sistem pakar ini sehingga sistem pakar ini dapat mendeteksi bakteri atau penyakit-penyakit lain yang membahayakan manusia. 


\section{DAFTAR PUSTAKA}

[1] I. M. Amalia, "Sistem Pakar Diagnosa Penyakit Paru-Paru Menggunakan Metode Certainty Factor Berbasis Web," Universitas Muhammadiyah Jember: Teknik Informatika, 2017.

[2] I. T. Dessetiadi, A. Pujianto, and M. G. Ardi, "Sistem Pakar untuk Mendiagnosa Penyakit Paru-Paru Menggunakan Algoritma Bayes," in Seminar Nasional Teknologi Informasi dan Multimedia 2016, 2016.

[3] M. Arhami, Konsep dasar sistem pakar. Yogyakarta: Andi, 2005.

[4] Sumiati, R. D. M. Badriyah, and A. Ariyani, "Sistem Pakar Untuk Diagnosa Penyakit Paru Paru Menggunakan Metode Certainty Factor Di Puskesmas Citangkil," J. ProTekInfo, vol. 4, 2017.

[5] Kusrini, Sistem Pakar Teori dan Aplikasi. Yogyakarta: Penerbit Andi, 2006.

[6] D. Palguna, "Sistem Pakar Diagnosis Penyakit Kulit Pada Kucing Menggunakan Metode Certainty Factor," Surabaya: STMIK STIKOM, 2013.

[7] T. Rab, Ilmu Penyakit Paru. Jakarta: Trans Info Media, 2010. 
MF Syaifulloh / Ubiquitous: Computers and its Applications Journal, Vol. 3, No. 2, Desember 2020, 59-64 